\title{
Linking plant composition and arthropod abundance to establish little bustard breeding requirements in pastureland dominated landscapes
}

\author{
Nuno Faria $\cdot$ João E. Rabaça $\cdot$ Manuel B. Morales
}

Received: 23 November 2011/ Accepted: 3 May 2012

(C) Springer Science+Business Media B.V. 2012

\begin{abstract}
Most research on steppe bird habitat selection has been focused on the effects of management regimes or vegetation structure. However, much less is known on how plant composition is related with steppe bird occurrence. We investigated microhabitat of little bustard territorial males and females during the nesting and chick-rearing season in areas with dominance of pastureland focusing on plant composition. We searched for relationships between preferred vegetation and arthropod abundance in order to identify the contribution of different vegetation typologies in providing essential trophic resources for the species. Surveys of little bustards were made using car and foot transects. Plant composition was obtained within a $50 \times 50 \mathrm{~cm}$ square at four sampling replicates and arthropod availability was sampled using a sweep net. Statistical procedures were conducted in three steps: (1) analysis of variance was used to identify at univariate level the plant composition and arthropod variables that were significantly related with both male and female occurrence sites; (2) principal components analysis was performed using the variables with significant results at univariate level; (3) model averaging on generalized linear and mixed models was applied to evaluate the selection probability of each principal component. The species occurs in sites with high floristic richness and high abundance of Fabaceae species, although plant composition differs from male to female sites. These variables were found to be crucial to provide higher abundances of arthropods, notably of Acrididea, Formicidae and some groups of Coleoptera which are decisive for the selection of displaying or female breeding sites.
\end{abstract}

N. Faria $(\bowtie) \cdot$ J. E. Rabaça

Laboratory of Ornithology (LabOr), Department of Biology, University of Évora, 7002-554 Évora, Portugal

e-mail: farnuno@gmail.com

N. Faria · J. E. Rabaça

Research Group on Mediterranean and Landscapes Ecosystems-ICAAM,

University of Evora,

7002-554 Évora, Portugal

N. Faria · M. B. Morales

Departamento de Ecología, Universidad Autónoma de Madrid, 28049 Madrid, Spain 